\title{
Kaygı, Belirsizliğe Tahammülsüzlük ve Karar Verme Arasındaki İlişkilerin İncelenmesi"
}

\author{
Şeyma Tantan Ulu ${ }^{* * 1}$ ve Barış Yaka²
}

Öz

Bu araştırma, üniversite öğrencilerinin; sürekli kaygı düzeyleri, belirsizliğe tahammülsüzlük düzeyleri ve karar verme davranışları arasında anlamlı ilişkiler bulunup bulunmadığını incelemek amacıyla, betimsel araștırma yaklaşımıyla gerçeklestirilmiștir. Araștırma, Ege Üniversitesi Eğitim Fakültesi lisans programlarında öğrenim gören öğrencilerle yürütülmüştür. Veri toplama sürecinin, her katılımcıya bireysel uygulama yapmayı gerektirmesi nedeniyle uygun örnekleme yoluna gidilerek 43 erkek ve 62 kadın olmak üzere toplam 105 katılımcıdan elde edilen veriler analiz edilmiștir. Araștırma kapsamında Bilgi Formu, Sürekli Kaygl Ölçeği, Belirsizliğe Tahammülsüzlük Ölçeği (uzun formu) ve Iowa Kumar Testi kullanılmıștır. Sürekli kaygı düzeyi, belirsizliğe tahammülsüzlük düzeyi ve karar verme davranışı arasındaki ilişkiler, Pearson moment korelasyon katsayısı analiziyle incelenmiştir. Neticede bu araştırmada; üniversite öğrencilerinin sürekli kaygı ve belirsizliğe tahammülsüzlük düzeyleri ile Iowa Kumar Testi performansları, diğer bir deyişle karar verme davranışları arasında anlamlı bir ilișki bulunmamıştır. Bunun yanı sıra, üniversite öğrencilerinin sürekli kaygı ve belirsizliğe tahammülsüzlük düzeyleri arasında anlamlı bir ilișki olduğu bulunmuștur. Iowa Kumar Testi kullanılarak bașka örneklemlerle ve başka popülasyonlarda benzer araştırmaların yapılmasının, karar verme davranışının ve ilișkili değişkenlerin Türkiye'de daha iyi anlaşılmasına yardımcı olacağına inanılmaktadır.

Anahtar Sözcükler

\author{
Karar verme \\ Kayg1 \\ Belirsizliğe \\ tahammülsüzlük \\ Iowa kumar testi \\ Beliren yetişkinlik \\ Makale Hakkında \\ Gönderim Tarihi \\ 20 Aralık 2019 \\ Kabul Tarihi \\ 06 Ocak 2020 \\ Makale Türi \\ Araştırma Makalesi
}

\section{Investigation of Relationships among Anxiety, Intolerance of Uncertainty, and Decision- Making*}

\section{Abstract}

The aim of this research is to investigate the relationships among trait anxiety, intolerance of uncertainty, and decision-making behavior. In this research, a descriptive research design was used. The research was conducted with the participation of volunteer university students who were enrolled in the undergraduate programs at Ege University Faculty of Education. Convenient sampling method was used and the data obtained from 105 participants (43 male and 62 female) were analyzed. Data collection instruments in the research were a Demographic Information Form, Trait Anxiety Inventory, Intolerance of Uncertainty Scale (long form), and Iowa Gambling Task. Correlational analysis was used to analyze the research data. As a result of the analysis, there was no statistically significant relationship between university students' trait anxiety level and Iowa Gambling Task performance. Also, there was no statistically significant relationship between the students' intolerance of uncertainty level and Iowa Gambling Task performance. However, it was concluded that there was a significant positive correlation between trait anxiety level and intolerance of uncertainty level of the students. The research findings were discussed in the light of the literature and some recommendations were made for future studies.
Keywords

Decision-making Anxiety

Intolerance of uncertainty

Iowa gambling task

Emerging adulthood

Article Info

Received

December 20, 2019

Accepted

January 06, 2020

Article Type

Research Paper

Atıf: Tantan Ulu, Ş. ve Yaka, B. (2020). Kaygı, belirsizliğe tahammülsüzlük ve karar verme arasındaki ilişkilerin incelenmesi. Ege Eğitim Dergisi, 21(1), 89-100. doi:10.12984/egeefd.661965

\footnotetext{
* Bu çalışma, Şeyma Tantan Ulu tarafindan Dr. Öğr. Üyesi Barış Yaka danışmanlığında hazırlanan yüksek lisans tezinden üretilmiştir. [This study was produced from master thesis prepared by Șeyma Tantan Ulu under the supervision of Asst. Prof. Barış Yaka]

${ }^{* *}$ Sorumlu Yazar/Corresponding Author

1 (D) Millî Eğitim Bakanlı̆̆ı̆, Hüseyin Avni Ateşoğlu Ortaokulu, Türkiye, seymatantan@gmail.com

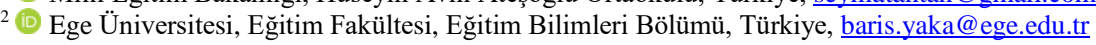




\section{Extended Abstract}

\section{Introduction}

Every purposeful action starts with a decision to achieve the goal (Gazzaniga, Ivry, \& Mangun, 2000). Decisionmaking processes are the gates that mediate between thought and action; any response, any cognitive task imaginable, such as memory-recognition, conceptual classification, problem solving, must be confirmed by a decision process. (Busemeyer, Hastie, \& Medin, 1995). Because it is vital, the decision-making process is a phenomenon that has been investigated and studied by many fields today (Busemeyer et al., 1995). The essence of decision-making is selecting one of the possibilities for a particular situation; in other words, it is possible to say that it is to choose an action, a word, a sentence or some combinations thereof (Damasio, 1994). When making decisions, according to rational behavior theories, it should be ensured that it's suitable for the purpose, it meets the current need, the total benefit is high, and the best available option in terms of total benefit or the process cost are (time, labor, money, etc.) low (Yates \& Estin, 1998). Therefore, decision-making is about making choices that will have the highest worth from a person's point of view and produce positive results (Gazzaniga et al., 2000; Yates \& Estin, 1998). Thus, in a way, researchers who study the phenomenon of decision-making aim to help people make more accurate decisions (Yates \& Estin, 1998). Descriptive decision theories in this direction, tries to define what people do, not what they should do (Gazzaniga et al., 2000). In the same vein, Damasio $(1994 ; 1995 ; 1996)$ proposed a number of views on the role and importance of emotions in people's decision-making processes. Accordingly, certain emotions match certain events, situations and results and constitute learning; this learning and matching also accelerates the prediction of possible outcomes of future scenarios (Damasio, 1994).

Resources for rational thinking in humans are often slow and prone to error; the function of emotions is to bridge the gaps of rationality (Laird \& Oatley, 1992). When one looks at human life, it can be said that one of the most common emotion is anxiety. Anxiety is an inevitable part of human being because of the need to survive, to maintain one's life and to give a sense of meaning to one's existence (Seligman \& Reichenberg, 2010).

Studies have shown that; intolerance of uncertainty is a psychological vulnerability factor associated with many psychological problems (Carleton et al., 2012; Counsell et al., 2017; Gentes \& Ruscio, 2011; McEvoy \& Mahoney, 2012; Norr et al., 2013; Shihata, McEvoy, \& Mullan, 2017; Yook, Kim, Suh, \& Lee, 2010). In daily life, we often need to make many choices and decisions with insufficient information, a limited time frame, conflicting feelings, and some level of uncertainty about the outcome (Koerner \& Dugas, 2006). From this perspective, the decision-making process for individuals who have intolerance of uncertainty or are highly prone to anxiety, it can become extremely compelling and stressful in a world where guaranteed choices are almost impossible. Therefore, this research was carried out to investigate whether there is a significant relationship between the anxiety levels, intolerance of uncertainty levels, and decision-making behaviors of university students.

As a result, the current research is expected to contribute to the literature on understanding the level of trait anxiety, intolerance of uncertainty, decision-making behavior, and the relationships among them. In addition, it is hoped that this research will provide a clue to increase the effectiveness of the counseling process about working with clients whom are in emerging adulthood stage and are experiencing anxiety-related problems, difficulties in uncertain situations, or difficulties in decision-making.

\section{Method}

According to the selected research topic; descriptive research approach (Christensen, 1988) was used because it was aimed to depict the relationships among the variables as they were, rather than looking for cause-effect relationships between the variables discussed.

The population of the research consists of students studying in the undergraduate programs of Ege University Faculty of Education in 2018-2019 academic year. Since the data collection process required individual administration to each participant, convenient sampling method (Christensen, Johnson, \& Turner, 2015) was used. Thus, the research was carried out with the participation of volunteers from the students in the mentioned academic year and undergraduate programs. For this purpose, first of all, 15 groups (class) were selected from the class levels of the mentioned undergraduate programs and the research was announced to the students in these classes. Data were then collected from 106 volunteer participants from selected classes. Because the data provided by a participant was incomplete, it was not included in the analysis. Data were collected from 105 participants (43 males $(41 \%)$ and 62 females (59\%) with a mean age of 22.2 years. 
Data Collection Instruments in this research are Demographic Information Form, Trait Anxiety Inventory (TAI), Intolerance of Uncertainty Scale (IUS-long form), and Iowa Gambling Task (IGT). Correlational analysis was used to analyze the research data. The relationship between trait anxiety level, intolerance of uncertainty and decision-making behavior was examined by Pearson moment correlation coefficient analysis.

\section{Findings}

There was a statistically significant moderate positive correlation between TAI and IUS total scores. In addition, as a result of the analysis made for the entire group; relationship between university students' IGT performance and trait anxiety level was not statistically significant. Also, the relationship between IGT performance and intolerance of uncertainty level was not statistically significant.

\section{Discussion and Conclusion}

Consequently, in this research, there was no significant relationship between university students' trait anxiety and IGT performance, and between intolerance of uncertainty and IGT performance. In addition, it was found that there was a significant relationship between the levels of trait anxiety and intolerance of uncertainty among university students.

In this research, the relationship between trait anxiety and intolerance of uncertainty may be considered as a repetition of the results in the mentioned literature. It can be said that individuals who are prone to anxiety are likely to be worried in any uncertain situation.

As a result, it can be understood from the literature that although there are differences, there are significant relationships between these variables. In this research although there is a significant relationship between the levels of trait anxiety and intolerance of uncertainty, there is no significant relationship between neither levels of trait anxiety and IGT performances nor intolerance of uncertainty and IGT performances. At this point, it can be said that, perception of risk and a sense of uncertainty to influence decision-making which was triggered by IGT might be inadequate for most of the participants. Although IGT is a carefully developed simulation of real-world decision-making situations, there is no real-life equivalent to win and loss in the game. At this point, in the studies to be conducted using IGT; participants may be offered some rewards (e.g. money, course credits to students) and some changes in IGT can be used (e.g. waiting time may be extended after each card selection) to increase uncertainty. In addition, the literature in Turkey; it is seen that the number of studies that measure decision-making behavior in situations similar to real life events, as it is tried to be provided by IGT, is still limited. Thus, by using IGT, in other samples and other populations while conducting similar studies, it is believed that the decision-making behavior and associated variables will help in better understanding in Turkey. 


\section{Giriş}

Amaçlı her eylem, hedefe ulaşmak için alınan bir kararla başlar (Gazzaniga, Ivry ve Mangun, 2000). Karar verme süreçleri, düşünce ve eylem arasında aracılık eden kapı görevlileridir (Busemeyer, Hastie ve Medin, 1995). Akla gelebilecek herhangi bir bilişsel görev ve işlem, hafiza-tanıma, kavramsal sınıflandırma, problem çözme gibi her tepki, bir karar verme süreci ile onaylanmalıdır (Busemeyer ve diğ., 1995). Bu kadar hayati olması nedeniyle karar verme süreci, günümüzde birçok alan tarafından araştırılan ve üzerinde çalışılan bir olgu olarak karşımıza çıkmaktadır (Busemeyer ve diğ., 1995). Karar vermenin özünün, belirli bir durumla ilgili olasılıklar içinden birini seçmek; yani bir eylemi, bir kelimeyi, bir cümleyi veya bunların bazı kombinasyonlarını seçmek olduğunu söylemek mümkündür (Damasio, 1994). Rasyonel davranış teorilerine göre karar verilirken, kararın amaca uygunluğuna, ihtiyacı karşılayıp karşılamadığına, toplam faydasının yüksek olmasına, toplam fayda açısından mevcut seçeneklerin en iyisi olmasına ve süreç maliyetinin (zaman, emek, para vb.) düşük olmasına dikkat edilmesi gerekmektedir (Yates ve Estin, 1998). Dolayısıyla karar verme, kişinin bakış açısına göre değeri en üst seviyede olacak, olumlu sonuçlar üretecek seçimler yapmakla ilgilidir (Gazzaniga ve diğ., 2000; Yates ve Estin, 1998). Böylece, karar verme olgusunu inceleyen araştırmacılar bir açıdan, insanlara daha isabetli kararlar almalarında yardımcı olmayı amaçlamaktadırlar (Yates ve Estin, 1998). Bu yönde betimleyici karar teorileri, insanların yapmaları gerekeni değil, esasen ne yaptıklarını tanımlamaya çalışmaktadır (Gazzaniga ve diğ., 2000). Aynı çerçevede Damasio (1994; 1995; 1996), insanların karar verme süreçlerinde duyguların rolü ve önemiyle ilgili birtakım görüşler ileri sürmüştür. Buna göre, belirli duygular ile belirli olaylar, durumlar ve sonuçlar eşleşerek bir öğrenme oluşturmakta, bu öğrenme ve eşleşme yoluyla da gelecekteki senaryoların muhtemel sonuçlarının tahmini hızlanmaktadır (Damasio, 1994).

Duygular, birey için önemli olaylara verilen ve öznel deneyimleri içeren tepkilerdir (Frijda, 1988). Duygunun tanımında tam bir uzlaşı olmamasına rağmen birçok ruh sağlığı uzmanının duygu tanımında; fizyolojik tepkiler, davranışsal tepkiler ve his olmak üzere üç ortak öğe bulunmaktadır (Gazzaniga ve diğg., 2000). İnsanlarda rasyonel düşünce için kaynaklar genellikle yavaş ve hataya eğilimlidir; duyguların işlevi ise rasyonalitenin boşluklarını kapatmaktır (Laird ve Oatley, 1992). İnsan hayatına bakıldığında en sık yaşanan duygulardan birinin kaygı olduğu söylenebilir. İnsanın hayatta kalma, hayatını sürdürme ve varlığına anlam katma ihtiyacından kaynaklanan kaygı, insan olmanın kaçınılmaz bir parçasıdır (Seligman ve Reichenberg, 2010). Gerçekçi kaygı, bir tehlikenin algılanmasıyla oluşan; kaçma, savunma vb. eylemle ilişkili, öz koruyucu bir tepkidir (Freud, 1916/2016a, 1933/2016b). Elbette bireylerin kaygıya yatkınlıkları istikrarlı bir biçimde farklılaşmaktadır (Spielberger, 1972). Sürekli kaygı düzeyi yüksek kişiler, düşük olan kişilere göre daha fazla sayıdaki uyaranı (durumu) tehlikeli veya tehdit edici olarak algılama ve bu tür durumlara, durumluk kaygının daha fazla artışıyla tepki verme eğilimindedirler (Spielberger, 1972). Nitekim, kaygı ile ilişkili problemlerin, bireylerin davranışını kaçma, kaçınma, güvenlik sağlama davranışları yoluyla kısıtladığı bilinmektedir (Sungur, 1997; Türkçapar, 2006).

Kaygı ile ilişkili problemleri birbirinden ayıran şey, kişinin kaygısının temasıdır. Bireyin, olumsuz bir olayın küçük de olsa ortaya çıkma ihtimalini son derece kabul edilemez bulma eğilimi olarak tanımlanan (Dugas, Gosselin ve Ladouceur, 2001) belirsizliğe tahammülsüzlük kavramı, ilk olarak yaygın kaygı bozukluğunun teması olarak ele alınmıştır. Bunun nedeni yaygın kaygıda, kişinin kaygısının belirli bir tema etrafında toplanmaması ve genelleşmesidir (Robichaud ve Dugas, 2015). Ayrıca, yapılan çalışmalar belirsizliğe tahammülsüzlüğün birçok psikolojik problemle ilişkili bir psikolojik kırılganlık faktörü olduğunu ortaya koymuştur (Carleton ve diğ., 2012; Counsell ve diğ., 2017; Gentes ve Ruscio, 2011; McEvoy ve Mahoney, 2012; Norr ve diğ., 2013; Shihata, McEvoy ve Mullan, 2017; Yook, Kim, Suh ve Lee, 2010). Günlük hayatta, genellikle yetersiz miktarda bilgi, sınırlı bir zaman dilimi, çelişkili duygular ve sonuçla ilgili bir miktar belirsizlikle birçok seçim ve değerlendirme yapmamız ve karar vermemiz gerekmektedir (Koerner ve Dugas, 2006). Bu açıdan bakıldığında, belirsizliğe tahammülsüzlüğü olan ya da kaygıya yatkınlığı yüksek olan bireyler için karar verme sürecinin, sonucu garantili seçimlerin neredeyse mümkün olmadığı bir dünyada son derece zorlayıcı ve stresli hâle gelebileceği söylenebilir. Buradan hareketle bu araştırma, üniversite öğrencilerinin sürekli kaygı düzeyleri, belirsizliğe tahammülsüzlük düzeyleri ve karar verme davranışları arasında anlamlı ilişkiler bulunup bulunmadığını incelemek amacıyla gerçekleştirilmiştir.

Arnett'e (2004) göre üniversite öğrencileri, 18-25 yaş arasını kapsayan ve kendine odaklanma, sayısız seçenekler, kimlik keşfi, değişkenlik ve arada kalmışlık ile karakterize edilen bir yaşam dönemi olan beliren yetişkinlik dönemindedir. Bu dönemin özellikle ruh sağlığ ruh sağlığı problemleri ile daha sık karşılaşılan bir dönem olduğu görülmektedir (Arnett, Kloep, Hendry ve Tanner, 2011). Bu dönemde en sık görülen ruh sağlığ problemleri yaygınlıklarına göre \% 22.3 ile kaygıyla ilişkili problemler, \% 22 ile madde kullanımı ve \% 11.9 ile dürtü kontrol bozuklukları olarak sıralanmıştır (Kessler, Chiu, Demler ve Walters, 2005). Sonuç olarak sürekli kaygı düzeyinin, belirsizliğe tahammülsüzlük düzeyinin, karar verme davranışının ve bunlar arasındaki ilişkilerin anlaşılması ile ilgili literatüre katkı sağlamasının yanı sıra bu araştırmanın, kaygı ile ilişkili problemler yaşayan, belirsizlik içeren durumlarda veya 
karar vermede güçlük yaşayan -özellikle beliren yetişkinlik dönemindeki- bireylerle çalışan psikolojik danışmanlara, psikolojik danışma sürecinin etkililiğini artırmada bir ipucu sunması umulmaktadır.

\section{Yöntem}

\section{Araştırmanın Deseni}

Seçilen araștırma konusuna göre bu araştırmada ele alınan değişkenler arasındaki neden-sonuç ilişkilerini aramak yerine, değişkenler arasındaki ilişkileri olduğu gibi resmetmek amaçlandığı için betimsel araştırma yaklaşımı (Christensen, 1988) kullanılmıştır.

\section{Evren ve Örneklem}

Araştırma, 2018-2019 öğretim yılında Ege Üniversitesi Eğitim Fakültesi lisans programlarında öğrenim gören öğrencilerle yürütülmüştür. Araştırmanın, eğitim fakültesi öğrencileri ile yürütülmesinin başlıca nedeni, fakülte bünyesinde, üniversiteye giriş sistemi kapsamında çeşitli puan türlerinden öğrenci alan çok sayıda programın bulunmasıdır. Esasen, veri toplama sürecinin, her katılımcıya bireysel uygulama yapmayı gerektirmesi nedeniyle uygun örnekleme (Christensen, Johnson ve Turner, 2015) yoluna gidilmiştir. Böylece araştırma, sözü edilen öğretim yılında ve lisans programlarında öğrenim gören öğrencilerden gönüllü olanların katılımı ile yürütülmüş̧ür. Bunun için önce, sözü edilen lisans programlarının sınıf düzeyleri arasından, veri toplanacak 15 grup (sınıf) kura ile seçilmiş ve bu sınıflardaki öğrencilere araştırma duyurulmuştur. Daha sonra, seçilen sınıflardan başvuran 106 gönüllü katılımcıdan veri toplanmıştır. Bir katılımcının sağladığı verilerde eksiklik olduğundan, o veriler analize katılmamıştır. Yaşlarının ortalaması 22.2 olan 18-30 yaş arası 43 erkek (\% 41) ve 62 kadın (\% 59) olmak üzere toplam 105 katılımcıdan elde edilen veriler analiz edilmiştir. Katılımcıların lisans programı, sınıf düzeyi ve cinsiyetine ilişkin sayı ve yüzdeler Tablo 1'de verilmiştir.

Tablo 1

Katılımcıların Lisans Programı, Sınıf Düzeyi ve Cinsiyetine İlişkin Sayı ve Yüzdeler

\begin{tabular}{|c|c|c|c|c|c|}
\hline \multirow{2}{*}{ Lisans Programı } & \multirow[b]{2}{*}{ Sınıf Düzeyi } & \multicolumn{3}{|c|}{$n$} & \multirow[b]{2}{*}{ Toplam \% } \\
\hline & & Katılıme1 & Kadın & Erkek & \\
\hline Bilgisayar ve Öğretim Teknolojileri Öğretmenliği & 4 & 13 & 6 & 7 & $\% 12.4$ \\
\hline Fen Bilgisi Öğretmenliği & 3 & 13 & 11 & 2 & $\% 12.4$ \\
\hline \multirow[t]{4}{*}{ Okul Öncesi Öğretmenliği } & 1 & 9 & 6 & 3 & $\% 15.2$ \\
\hline & 2 & 3 & 2 & 1 & \\
\hline & 3 & 3 & 3 & - & \\
\hline & 4 & 1 & 1 & - & \\
\hline \multirow[t]{2}{*}{ Özel Eğitim Öğretmenliği } & 2 & 7 & 2 & 5 & $\% 14.3$ \\
\hline & 3 & 8 & 5 & 3 & \\
\hline Rehberlik ve Psikolojik Danışmanlık & 4 & 9 & 8 & 1 & $\% 8.6$ \\
\hline Resim-İş Öğretmenliği & 4 & 3 & 2 & 1 & $\% 2.9$ \\
\hline Sosyal Bilgiler Öğretmenliği & 1 & 12 & 1 & 11 & $\% 11.4$ \\
\hline \multirow[t]{2}{*}{ Sınıf Öğretmenliği } & 2 & 6 & 6 & - & $\% 7.6$ \\
\hline & 3 & 2 & 2 & - & \\
\hline \multirow[t]{2}{*}{ Türkçe Öğretmenliği } & 3 & 12 & 5 & 7 & $\% 15.2$ \\
\hline & 4 & 4 & 2 & 2 & \\
\hline Toplam & & 105 & 62 & 43 & \\
\hline
\end{tabular}

Tablo 1'e göre, katılımcıların \% 20'si $(n=21) 1$. sinıfta, \% 15'i $(n=16) 2$. sinıfta, \% 36's1 $(n=38) 3$. sinıfta ve $\% 29$ 'u $(n=30) 4$. sınıfta öğrenim gören öğrencilerden oluşmaktadır.

\section{Veri Toplama Araçları}

Araştırma kapsamında Bilgi Formu (BF), Sürekli Kaygı Ölçeği (SKÖ), Belirsizliğe Tahammülsüzlük Ölçeği (BTÖ-uzun formu) ve Iowa Kumar Testi (IKT) kullanılmıştır. Veri toplama araçları ile ilgili bilgiler aşağıda sunulmuştur. 
Bilgi Formu. BF, araştırmacı tarafından hazırlanmıştır. Bu formla katılımcıların yaş, cinsiyet, öğrenim gördükleri lisans programı ve sınıf bilgileri elde edilmiştir.

Sürekli Kaygı Ölçeği. Öner ve Le Compte’a (1983) göre, ölçeğin orijinal formu 1970 yılında C. D. Spielberger, R. L. Gorsuch ve R. Lushene tarafından geliştirilmiş olup 1974-1976 yılları arasında Necla Öner ve Ayhan Le Compte tarafından Türkçeye uyarlanmıştır. Toplamda 40 sorudan oluşan ölçeğin 1-20 arasındaki soruları durumluk kaygıyı ve 21-40 arasındaki soruları sürekli kaygıyı ölçmeye yöneliktir. Yapılan güvenilirlik çalışmasında güvenilirlik katsayısı; Durumluk Kaygı Ölçeği (DKÖ) için .94-.96 arasında ve SKÖ için .83-.87 arasında bulunmuştur. Madde güvenilirliği korelasyonlarına bakıldığında, SKÖ için .34-.72 arasında ve DKÖ için .42-.85 arasında olduğu görülmüştür. Test-tekrar test güvenilirliği katsayılarının ise SKÖ için .71-.86 arasında ve DKÖ için .26-.68 arasında değiştiği görülmüştür. Yapı geçerliliği ve kriter geçerliliği çalışmaları da yapılmış ve ölçeğin Türkçe formunun geçerli ve güvenilir olduğu sonucuna ulaşılmıştır (Öner ve Le Compte, 1983). Örneğin, normal $(n=49)$ ve hasta gruplar $(n=177)$ üzerinde, ölçeklerin yapı geçerliliği deneysel olarak sınanmıştır (Öner, 1977; akt. Öner ve Le Compte, 1983). Üniversite öğrencilerinin normal grubu, diş tedavisi ve çeşitli cerrahi hastaları ile psikiyatri hastalarının ise hasta gruplarını oluşturduğu çalışmada, stres (sınav, tedavi, ameliyat) hâlinde elde edilen yüksek durumluk kaygı puanları, stres ortadan kalktıktan sonra anlamlı düzeyde düşme göstermiş ancak aynı değişim sürekli kaygı puanlarında görülmemiştir (Öner, 1977; akt. Öner ve Le Compte, 1983). Kriter geçerliliği kapsamında ise normallerle psikiyatri hastaları arasında yapılan bir karşılaştırmada (Öner, 1977; akt. Öner ve Le Compte, 1983); psikiyatri hastalarının normallerden anlamlı düzeyde ortalama 16.97 sürekli kaygı ve 14.25 durumluk kaygı puanı yüksek olduğu ve psikiyatri hastalarının durumunu açıklamada sürekli kaygının \% 22 oranında katkıda bulunduğu saptanmıştır.

Bu araştırma kapsamında, sadece SKÖ kullanılmıştır ve bu ölçeğe ait Cronbach $\alpha$ değeri .85 olarak bulunmuştur. Buna göre, SKÖ’nün bu araştırmadaki güvenilirliğinin, orijinal formunu Türkçeye uyarlama çalışmasındaki gibi yüksek düzeyde olduğu sonucuna ulaşılmıştır.

SKÖ; (1) Hemen hemen hiçbir zaman, (2) Bazen, (3) Çoğu zaman, (4) Hemen her zaman, şeklinde cevaplanan Likert tipi bir kendini değerlendirme formudur. Ölçekten elde edilecek puan, 20-80 arasında değişmekte olup yüksek puan yüksek kaygı düzeyine işaret etmektedir. SKÖ’de yedi tane ters madde bulunmaktadır. 36 puanın altı, düşük kaygı düzeyini gösterirken; 36-41 arasındaki puanlar normal kaygı düzeyini ve 41 üzeri puanlar kayg1 düzeyinin yüksek olabileceğini göstermektedir (Öner ve Le Compte, 1983).

Belirsizliğe Tahammülsüzlük Ölçeği. Ölçeğin orijinal Fransızca versiyonu Freeston, Rhéaume, Letarte, Dugas ve Ladouceur (1994) tarafından geliştirilmiş olup belirsiz durumlara duygusal, bilişsel ve davranışsal tepkileri, belirsizliğin etkilerini ve geleceği kontrol etme girişimlerini değerlendiren 27 maddeden oluşmaktadır. İngilizceye Buhr ve Dugas (2002) tarafından uyarlanmıştır. Ölçeğin İngilizce formunun iç tutarlılı̆̆ 1.94 olarak bulunmuştur. Madde-toplam korelasyonları .36-.77 arasında değişmektedir. Test-tekrar test güvenilirliği ise .74 olarak hesaplanmıştır. Ölçek, dört faktörlü bir yapıya sahiptir ve faktörler arasındaki korelasyon .42-.69 arasında değişmektedir. Dört faktörün tamamının toplam BTÖ puanıyla korelasyonu .82-.94 arasında değişmektedir (Buhr ve Dugas, 2002).

Ölçeğin Türkçeye uyarlanması, Sarı ve Dağ (2009) tarafından Hacettepe Üniversitesinde öğrenim gören 441 öğrencinin katılımıyla yapılmıştır. Yapılan çalışmada 27 maddeden oluşan ölçeğin iç tutarlılığ1 .93, test-tekrar test güvenilirliği .66 olarak bulunmuştur. Madde faktör korelasyonları .40-.77 arasında değişmektedir. Yapılan faktör analizinde: a) Belirsizlik stres verici ve üzücüdür, b) Belirsizlik ile ilgili olumsuz benlik değerlendirmeleri, c) Geleceği bilmemek rahatsız edicidir, d) Belirsizlik eyleme geçmeyi engeller, şeklinde dört faktörlü bir yapı elde edilmiştir. Bu dört faktörün, toplam varyansın sırasılla \% 16, \% 13, \% 11 ve \% 8.9'unu açıkladığı görülmüştür. Beşinci faktör tek bir maddeden (10. madde) oluştuğu ve madde-toplam korelasyonu ( $r=$ .29) düşük olduğu için, ölçeğin 21. maddesi ise hiçbir alt ölçeğe girmediği için, bu iki madde ölçekten çıkarılmıştır.

$\mathrm{Bu}$ araştırmada BTÖ toplam puanına ait Cronbach $\alpha$ değeri .92 olarak bulunmuştur. Ölçeğin 1. faktörüne ait Cronbach $\alpha$ değeri .85, 2. faktörüne ait Cronbach $\alpha$ değeri .73, 3. faktörüne ait Cronbach $\alpha$ değeri .73 ve 4 . faktörüne ait Cronbach $\alpha$ değeri .68 olarak bulunmuştur. Ölçeğin 4. faktörünün güvenilirlik katsayısının görece düşük olmasının sebebinin, 4. faktörün madde sayısının az olmasından kaynaklandığı söylenebilir. Buna göre, BTÖ’nün bu araştırmadaki güvenilirliğinin Türkçeye uyarlama çalışmasında olduğu gibi yüksek düzeyde olduğu sonucuna ulaşılmıştır.

BTÖ’nün Türkçe formu toplam 27 maddeden oluşmaktadır. BTÖ; (1) Beni hiç tanımlamıyor ile (5) Beni tam olarak tanımlıyor, arasında değişen şekilde cevaplanan bir dereceleme ölçeğidir. Ölçekte ters puanlanan bir madde yoktur. Hiçbir faktöre girmemesi nedeniyle 10 ve 21. madde puanlamaya dâhil edilmemektedir. Böylece bireyin ölçekten alabileceği puan 25-125 arasında değişmekte olup yüksek puan bireyin, belirsizliğe tahammülsüzlük düzeyinin yüksek olduğunu göstermektedir. 
Iowa Kumar Testi. Beyninin ventromedial bölgesi zarar görmüş insanların karar verme davranışlarında bozulmalar olduğunu fark eden Bechara, Damasio, Damasio ve Anderson (1994), bu durumu inceleyebilecekleri nöropsikolojik bir test geliştirmiştir. IKT; öncül ve sonuçların belirsizliğini, ödül ve ceza durumlarını içermesiyle, gerçek hayattaki karar verme davranışının bir simülasyonudur (Bechara ve diğ., 1994; Bechara, Damasio, Tranel ve Damasio, 1997).

Bu araştırmada, Türkiye'de IKT'nin norm çalışmalarını yapmış olan İçellioğlu'ndan (2015) elde edilen ve Dr. Gülay Büyükaksoy Kaplan tarafından yazılmış olan IKT programı kullanılmıştır. Bir bilgisayar programı olan IKT uygulamasının başında, katılımcıya dört kart destesi (A, B, C, D) ve 2000 birim para verilir. Katılımcıdan, tüm kartlar bitene kadar kart seçmeye devam etmesi istenir. Katılımcıya, en az miktarda para kaybedeceği ve en çok miktarda para kazanacağı seçimler yapması gerektiği, her seçiminden sonra ekranda, kazandığı ve kaybettiği paranın miktarının yazacağı, buna bakarak devam etmesi gerektiği söylenir.

A ve B desteleri, kısa vadede yüksek kazanca, fakat uzun vadede kazançtan çok kayba sebep olurken; C ve D desteleri, kısa vadede düşük kayıp ve uzun vadede kayıplardan fazla kazanç sağlayan destelerdir. Yüz adet kart seçimi tamamlandığında oyun durur. Katılımcılara, oyunda toplam kaç kart olduğu, destelerin avantaj ve dezavantaj durumları, hangi destelerden seçim yapacakları hakkında bilgi verilmez (Bechara ve diğ., 1994). Bu açıdan bakıldığında katılımcı, uygulama boyunca belirsizlik içindedir. IKT performansıyla ilgili, katılımcının testin tamamında seçtiği avantajlı deste sayısından dezavantajlı deste sayısının çıkarılmasıyla toplam net puan (toplam puan) ve sırasıyla her 20 seçim için bu işlem tekrarlanarak her 20'lik kart bloğu için de beş ayrı net puan elde edilir (İçellioğlu, 2015).

\section{Veri Toplama Süreci}

İlk olarak, araştırmada katılımcı olmak için başvuran 106 gönüllü öğrenci ile bireysel randevular oluşturulmuştur. Veri toplama sürecinde, Ege Üniversitesi Eğitim Fakültesi Psikolojik Danışma Biriminde yer alan görüşme odaları kullanılmıştır. Veri toplama öncesinde her katılımcıya, araştırma ile ilgili bilgilerin bulunduğu onam formu okutulmuş ve araştırma hakkında gerekli bilgiler aktarılmış, varsa, katılımcının araştırma ile ilgili soruları cevaplanmıștır. Ardından BF’yi, SKÖ’yü ve BTÖ’yü doldurması istenmiștir. Son olarak katılımcıya, bilgisayar temelli olan IKT ile ilgili bilgi formu ve yönerge verilmiştir. Katılımcı, tüm kart seçimlerini tamamlayana kadar uygulama devam etmiştir. IKT’nin uygulanma süresi, her katılımcı için yaklaşık 15 dakika sürmüştür.

\section{Veri Analizi}

Sürekli kaygı düzeyi, belirsizliğe tahammülsüzlük düzeyi ve karar verme davranışı arasındaki ilişkiler, Pearson moment korelasyon katsayısı analiziyle incelenmiştir.

\section{Etik Konular}

Araştırma için, etik kurul izni alınmıştır. Tüm katılımcılara araştırma ile ilgili bilgilendirilmiş onam formu sunulmuştur. Veriler, araştırmaya gönüllü olarak katılan öğrencilerden toplanmıştır.

\section{Bulgular}

Araştırmanın değişkenlerine ilişkin betimsel bulgular Tablo 2'de verilmiştir.

Tablo 2

Değişkenlere İlişkin Betimsel Bulgular

\begin{tabular}{llcc}
\hline Değişkenler & Cinsiyet & $\bar{X}$ & $S S$ \\
\hline SKÖ Toplam Puanı & Kadın & 46.06 & 8.88 \\
& Erkek & 41.65 & 7.39 \\
BTÖ Toplam Puanı & Kadın & 75.44 & 16.55 \\
& Erkek & 71.44 & 19.54 \\
IKT Toplam Puanı & Kadın & -3.24 & 15.67 \\
& Erkek & 6.65 & 24.38 \\
IKT Avantajlı Seçim Sayısı & Kadın & 48.39 & 7.84 \\
& Erkek & 53.33 & 12.19 \\
IKT Dezavantajlı Seçim Sayısı & Kadın & 51.63 & 7.83 \\
& Erkek & 46.67 & 12.19 \\
\hline
\end{tabular}

Kadın, $n=62$; Erkek, $n=43$. 
Tablo 2'de görüldüğü gibi, kadınların SKÖ ve BTÖ’nün toplam puan ortalamalarının, erkeklerin puan ortalamalarından yüksek olduğu bulunmuştur. Bunun yanında erkeklerin IKT avantajlı seçim sayısı ve IKT toplam puan ortalamalarının, kadınların ortalamalarından yüksek olduğu ve kadınların IKT dezavantajlı seçim sayısı ortalamasının, erkeklerin ortalamasından yüksek olduğu bulunmuştur.

Araştırmanın değişkenleri arasındaki ilişkilerin incelenmesine ilişkin bulgular Tablo 3’te verilmiştir.

Tablo 3

Değişkenler Arasındaki İlişkilerin İncelenmesine İlişkin Bulgular

\begin{tabular}{|c|c|c|c|c|c|}
\hline Değişkenler & $\begin{array}{c}\text { SKÖ Toplam } \\
\text { Puanı }\end{array}$ & $\begin{array}{c}\text { BTÖ Toplam } \\
\text { Puanı }\end{array}$ & $\begin{array}{c}\text { IKT Toplam } \\
\text { Puanı } \\
\end{array}$ & $\begin{array}{c}\text { IKT Avantajlı } \\
\text { Seçim Sayısı }\end{array}$ & $\begin{array}{c}\text { IKT Dezavantajlı } \\
\text { Seçim Sayısı }\end{array}$ \\
\hline SKÖ Toplam Puanı & - & - & - & - & - \\
\hline BTÖ Toplam Puanı & $.607 * *$ & - & - & - & - \\
\hline IKT Toplam Puanı & .135 & .117 & - & - & - \\
\hline IKT Avantajlı Seçim Sayısı & .135 & .118 & $1 * *$ & - & - \\
\hline IKT Dezavantajlı Seçim Sayısı & -.134 & -.117 & $-1 * *$ & $-1 * *$ & - \\
\hline
\end{tabular}

$N=105, * * p<.01$

SKÖ ve BTÖ’nün toplam puanları arasında istatistiksel olarak anlamlı orta düzeyde pozitif korelasyon olduğu bulunmuştur. Bunun yanında, grubun tamamı için yapılan analiz sonucunda, SKÖ ve BTÖ’nün toplam puanları ile IKT avantajlı seçim sayısı, IKT dezavantajlı seçim sayısı ve IKT toplam puanı (IKT performansı) arasında istatistiksel olarak anlamlı ilişkiler olmadığı görülmüștür.

\section{Sonuç ve Tartışma}

Bu araştırmada, üniversite öğrencilerinin sürekli kaygı ve belirsizliğe tahammülsüzlük düzeyleri ile IKT performansları, diğer bir deyişle karar verme davranışları arasında anlamlı bir ilişki bulunmamıştır. Bunun yanı sıra, üniversite öğrencilerinin sürekli kaygı ve belirsizliğe tahammülsüzlük düzeyleri arasında anlamlı bir ilişki olduğu bulunmuştur. Literatüre bakıldığında; sürekli kaygı (Sarı, 2007; Sarı ve Dağ, 2009), yaygın kaygı (Buhr ve Dugas, 2012; Counsell ve diğ., 2017; Dugas, Marchand ve Ladouceur, 2005; Gentes ve Ruscio, 2011; Khawaja ve McMahon, 2011), sosyal kaygı (Counsell ve diğ., 2017; Khawaja ve McMahon, 2011; Norr ve diğ., 2013; Shihata ve diğ., 2017), obsesif-kompulsif bozukluk (Gentes ve Ruscio, 2011; Khawaja ve McMahon, 2011; Norr ve diğ., 2013), panik bozukluğu (Shihata ve diğ., 2017), ayrılma kaygısı (Değirmenci, 2017) ve belirsizliğe tahammülsüzlük arasında ilişki bulunduğunu belirten çeşitli araştırmaların olduğu görülmektedir. Buna göre belirsizliğe tahammülsüzlüğün hem sürekli kaygı hem de kaygı ile ilgili diğer problemlerle ilişkili olduğu anlaşılmaktadır. Bu araştırmada da sürekli kaygı ve belirsizliğe tahammülsüzlüğün ilişkili bulunması, literatürde belirtilen sonuçların bir tekrarı olarak düşünülebilir. Sonuç olarak kaygıya yatkınlığı yüksek olan bireylerin, herhangi bir belirsiz durumda da kaygılanması muhtemeldir denebilir.

Literatürdeki kaygı düzeyi ile karar verme davranışı arasındaki ilişkiyi açıklamaya çalışan araştırmalara bakıldığında, bu iki değişken arasında çoğunlukla anlamlı fakat farklı ilişkiler bulunduğu görülmektedir. Bazı araştırmacılar yüksek kaygı düzeyine sahip bireylerin, IKT performanslarında düşük risk düşük kazanç sağlayan seçimler yaptığını; riskten kaçınmayı, kaygı düzeyi düşük olan bireylere göre daha çabuk öğrendiğini; riskten kaçınma davranışlarının yüksek olduğunu (Maner ve Schmidt, 2006; Maner ve diğ., 2007; Mueller, Nguyen, Ray ve Borkovec, 2010; Raghunathan ve Pham, 1999); sürekli kaygı ile karar verme davranışı arasında pozitif bir ilişki olduğunu ve yüksek kaygı düzeyinin karar verme davranışını olumlu yönde etkilediğini (Werner, Duschek ve Schandry, 2009) belirtmiştir. Bazı araştırmacılar ise yüksek sürekli kaygı düzeyine sahip bireylerin IKT performansının düştüğünü ve karar verme sürecinin bozulduğunu rapor etmiştir (Çobanoğlu, 2017; de Visser, Van der Knaap, Van den Loo ve Van der Weerd, 2010; Gray, 1999; Miu, Heilman ve Houser, 2008).

Belirsizliğe tahammülsüzlük düzeyi ile karar verme davranışı arasındaki ilişkiyi inceleyen araştırmalara bakıldığında ise burada da farklı sonuçların elde edildiği görülmektedir. Ladouceur, Talbot ve Dugas (1997); belirsizliğe tahammülsüzlük düzeyi yüksek olan bireylerin, belirsiz durumlarda karar vermek için daha fazla kesinliğe ihtiyaç duyduklarını belirtmiştir. Luhmann, Ishida ve Hajcak (2011) da yüksek belirsizliğe tahammülsüzlük düzeyi ile kısa bekleme süresi ve hızlıca daha değersiz, daha riskli ödülün seçilme sıklığ arasında pozitif bir ilişki olduğunu; bunun yanında, yüksek belirsizliğe tahammülsüzlük düzeyinin, olumsuz sonuçlara daha fazla duyarlılıkla ilişkili olduğunu belirtmiştir. Carleton ve diğerleri (2016) ise belirsizliğe tahammülsüzlük düzeyi ile IKT performansı arasındaki ilişkinin, farklı özelliklerdeki iki katılımcı grubu kullanarak inceledikleri araştırmanın sonucunda, gruplardan birinde ters yönde diğerinde ise aynı yönde olduğunu bulmuştur. 
Sonuç olarak literatürden anlaşıldığı üzere gerek sürekli kaygı düzeyi gerekse belirsizliğe tahammülsüzlük düzeyi ile karar verme davranışı arasındaki ilişkileri inceleyen araştırmaların sonuçlarında farklılıklar olmakla birlikte, söz konusu değişkenler arasında anlamlı ilişkilerin bulunduğu görülmektedir. Bu araştırmada ise sürekli kaygı ve belirsizliğe tahammülsüzlük düzeyleri arasında anlamlı bir ilişsinin olduğu bulunmakla birlikte, sürekli kaygı ve belirsizliğe tahammülsüzlük düzeyleri ile IKT performansları arasında anlamlı bir ilişkinin bulunmamasıyla ilgili, IKT’nin, karar vermeyi etkilemesi için risk algısını ve belirsizlik duygusunu tetiklemekte katılımcıların çoğunda yetersiz kalmış olabileceği düşünülmektedir. IKT, her ne kadar gerçek hayattaki karar verme durumunun özenle geliştirilmiş bir simülasyonu olsa da oyundaki kazanç ve kaybın gerçek hayatta bir karşılığı yoktur. Bu noktada, IKT kullanılarak gerçekleştirilecek araştırmalarda, IKT uygulaması kapsamında katılımcılara bazı ödüller (ör. para, öğrencilere ders kredisi) verilmesi ve belirsizliği artıracak şekilde IKT’de bazı değişiklikler (ör. her kart seçiminden sonra bekleme süresi uzatılabilir) yapılması önerilebilir. Ayrıca, Türkiye'de literatürde IKT ile sağlanmaya çalışıldığı gibi karar verme davranışının, gerçek yaşam olaylarına benzer durumlarda ölçüldüğü araştırmaların sayısının hâlen sınırlı olduğu görülmektedir. Dolayısıyla, IKT kullanılarak başka ve daha büyük örneklemlerle ve başka popülasyonlarda, örneğin başka üniversite ve fakültelerde benzer araştırmaların yapılmasının, özellikle beliren yetişkinlik dönemindeki bireylerin karar verme davranışının ve ilişkili değişkenlerin Türkiye'de daha iyi anlaşılmasına yardımcı olacağına inanılmaktadır.

Etik Kurul İzin Bilgisi: Bu araştırma, Ege Üniversitesi Sosyal ve Beşerî Bilimler Bilimsel Araştırma ve Yayın Etiği Kurulunun 28/03/2019 tarihli 04/16 sayll Kararl ile alınan izinle yürütülmüştür. 


\section{Kaynakça/References}

Arnett, J. J. (2004). Emerging adulthood: The winding road from the late teens through the twenties. New York: Oxford University. Retrieved from https://b-ok.cc/book/1197556/86ed4a

Arnett, J. J., Kloep, M., Hendry, L. B., \& Tanner, J. (2011). Debating emerging adulthood: Stage or process? New York: Oxford University. Retrieved from https://b-ok.cc/book/3319241/b93fbe

Bechara, A., Damasio, A. R., Damasio, H., \& Anderson, S. W. (1994). Insensitivity to future consequences following damage to human prefrontal cortex. Cognition, 50, 7-15. doi:10.1016/0010-0277(94)90018-3

Bechara, A., Damasio, H., Tranel, D., \& Damasio, A. R. (1997). Deciding advantageously before knowing the advantageous strategy. Science, 275, 1293-1295. doi:10.1126/science.275.5304.1293

Buhr, K., \& Dugas, M. J. (2002). The intolerance of uncertainty scale: Psychometric properties of the English version. Behavior Research and Therapy, 40, 931-945. doi:10.1016/s0005-7967(01)00092-4

Buhr, K., \& Dugas, M. J. (2012). Fear of emotions, experiential avoidance, and intolerance of uncertainty in worry and generalized anxiety disorder. International Journal of Cognitive Therapy, 5(1), 1-17. doi:10.1521/ijct.2012.5.1.1

Busemeyer, J., Hastie, R., \& Medin D. L. (Eds.) (1995). Decision making from a cognitive perspective. California: Academic.

Carleton, R. N., Duranceau, S., Shulman, E. P., Zerff, M., Gonzales, J., \& Mishra, S. (2016). Self-reported intolerance of uncertainty and behavioural decisions. Journal of Behavior Therapy and Experimental Psychiatry, 51, 58-65. doi:10.1016/j.jbtep.2015.12.004

Carleton, R. N., Mulvogue, M. K., Thibodeau, M. A., McCabe, R. E., Antony, M. M., \& Asmundson, G. J. G. (2012). Increasingly certain about uncertainty: Intolerance of uncertainty across anxiety and depression. Journal of Anxiety Disorders, 26, 468-479. doi:10.1016/j.janxdis.2012.01.011

Christensen, L. B. (1988). Experimental methodology (4th ed.). Newton, MA: Allyn and Bacon.

Christensen, L. B., Johnson, R. B., \& Turner, L. A. (2015). Research methods, design and analysis (12th ed.). Westford: Pearson. Retrieved from https://b-ok.cc/book/2838323/273556

Counsell, A., Furtado, M., Iorio, C., Anand, L., Canzonieri, A., Fine, A., Fotinos, K., Epstein, I., \& Katzman, M. A. (2017). Intolerance of uncertainty, social anxiety, and generalized anxiety: Differences by diagnosis and symptoms. Psychiatry Research, 252, 63-69. doi.org/10.1016/j.psychres.2017.02.046

Çobanoğlu, S. (2017). Durumluk ve sürekli kaygı ile benlik saygısının karar verme davranışıly ilişkisinin deneysel yöntemle incelenmesi. (Yayımlanmamış yüksek lisans tezi). Doğuş Üniversitesi, İstanbul.

Damasio, A. R. (1994). Descartes' error: Emotion, reason and the human brain. New York: Avon.

Damasio, A. R. (1995). Toward a neurobiology of emotion and feeling: operational concepts and hypotheses. Neuroscientist, 1(19), 19-25. doi:10.1177/107385849500100104

Damasio, A. R. (1996). The somatic marker hypothesis and the possible functions of the prefrontal cortex [and discussion]. Philosophical Transactions of the Royal Society B: Biological Sciences, 351, 1413-1420. doi:10.1098/rstb.1996.0125

de Visser, L., Van der Knaap, L. J., Van den Loo, A. J. A. E., \& Van der Weerd, C. M. M. (2010). Trait anxiety affects decision-making differently in healthy men and women: Towards gender-specific endophenotypes of anxiety. Neuropsychologia, 48, 1598-1606. doi:10.1016/j.neuropsychologia.2010.01.027

Değirmenci, S. S. (2017). Gebelikte ayrlma anksiyetesi ve belirsizliğe tahammülsüzlükle ilişkisi. (Yayımlanmamış tıpta uzmanlık tezi). Osmangazi Üniversitesi, Eskişehir.

Dugas, M. J., Gosselin, P., \& Ladouceur, R. (2001). Intolerance of uncertainty and worry: Investigating specificity in a nonclinical sample. Cognitive Therapy and Research, 25(5), 551-558. doi:10.1023/a:1005553414688

Dugas, M. J., Marchand, A., \& Ladouceur, R. (2005). Further validation of a cognitive-behavioral model of generalized anxiety disorder: Diagnostic and symptom specificity. Anxiety Disorders, 19, 329-343. doi:10.1016/j.janxdis.2004.02.002

Freeston, M. H., Rhéaume, J., Letarte, H., Dugas, M. J., \& Ladouceur, R. (1994). Why do people worry? Personality and Individual Differences, 17, 791-802. doi:10.1016/0191-8869(94)90048-5 
Freud, S. (2016a). Psikanalize giriş dersleri (6. baskı). (S. Budak, çev.). İstanbul: Öteki.

Freud, S. (2016b). Psikanalize yeni giriş dersleri (6. baskı). (S. Budak, çev.). İstanbul: Öteki.

Frijda, N. H. (1988). The laws of emotion. American Psychologist, 43(5), 349-358. Retrieved from http://dx.doi.org/10.1037/0003-066X.43.5.349

Gazzaniga M. S., Ivry R. B., \& Mangun G. R. (2000). Cognitive neuroscience: The biology of the mind (2nd ed.). New York: W. W. Norton and Company. Retrieved from https://b-ok.cc/book/2623203/e01e50

Gentes, E. L., \& Ruscio, A. M. (2011). A meta-analysis of the relation of intolerance of uncertainty to symptoms of generalized anxiety disorder, major depressive disorder, and obsessive-compulsive disorder. Clinical Psychology Review, 31, 923-933. doi:10.1016/j.cpr.2011.05.001.

Gray, J. R. (1999). A bias toward short-term thinking in threat related negative emotional states. Personality and Social Psychology Bulletin, 25, 65-75. doi:10.1177/0146167299025001006

İçellioğlu, S. (2015). Iowa kumar testi: Normatif veriler ve yürütücü işlevlerle ilişkisi. Düşünen Adam: The Journal of Psychiatry and Neurological Sciences, 28, 222-230. doi:10.5350/DAJPN2015280305

Kessler, R. C., Chiu, W. T., Demler, O., \& Walters, E. E. (2005). Prevalence, severity, and comorbidity of $12-$ month DSM-IV disorders in the national comorbidity survey replication. Archieves of General Psychiatry, 62(6), 617-627. doi:10.1001/archpsyc.62.6.617

Khawaja, N. G., \& McMahon, J. (2011). The relationship of meta-worry and intolerance of uncertainty with pathological worry, anxiety, and depression. Behaviour Change, 28, 165-180. doi:10.1375/bech.28.4.165

Koerner, N., \& Dugas, M. J. (2006). A cognitive model of generalized anxiety disorder: The role of intolerance of uncertainty. In G. C. L. Davey \& A. Wells (Eds.), Worry and its psychological disorders: Theory, assessment and treatment (pp. 201-216). West Sussex: Wiley.

Ladouceur, R., Talbot, F., \& Dugas, M. J. (1997). Behavioral expressions of intolerance of uncertainty in worry. Behavior Modification, 21, 355-371. doi:10.1177/01454455970213006

Laird, P. N. J., \& Oatley, K. (1992). Basic emotions, rationality, and folk theory. Cognition and Emotion, 6(3/4), 201-223. doi:10.1080/02699939208411069

Luhmann, C. C., Ishida, K., \& Hajcak, G. (2011). Intolerance of uncertainty and decisions about delayed, probabilistic rewards. Behavior Therapy, 42(3), 378-386. doi:10.1016/j.beth.2010.09.002

Maner, J. K., \& Schmidt, N. B. (2006). The role of risk avoidance in anxiety. Behavior Therapy, 37(2), 181189. doi:10.1016/j.beth.2005.11.003

Maner, J. K., Richey, J. A., Cromer, K., Mallott, M., Lejuez, C., Joiner, T. E., \& Schmidt, N. B. (2007). Dispositional anxiety and risk-avoidant decision making. Personality and Individual Differences, 42(4), 665-675. doi:10.1016/j.paid.2006.08.016

McEvoy, P., \& Mahoney, A. E. J. (2012). To be sure, to be sure: Intolerance of uncertainty mediates symptoms of various anxiety disorders and depression. Behavior Therapy, 43(3), 533-545. doi:10.1016./j.beth.2011.02.007

Miu, A. C., Heilman, R. M., \& Houser, D. (2008). Anxiety impairs decision-making: Psychophysiological evidence from an Iowa gambling task. Biological Psychology, 77(3), 353-358. doi:10.1016/j.biopsycho.2007.11.010

Mueller, E. M., Nguyen, J., Ray, W. J., \& Borkovec, T. D. (2010). Future-oriented decision-making in generalized anxiety disorder is evident across different versions of the Iowa gambling task. Journal of Behavior Therapy and Experimental Psychiatry, 41(2), 165-171. doi:10.1016/j.jbtep.2009.12.002

Norr, A. M., Oglesby, M. E., Capron, D. W., Raines, A. M., Korte, K. J., \& Schmidt, N. B. (2013). Evaluating the unique contribution of intolerance of uncertainty relative to other cognitive vulnerability factors in anxiety psychopathology. Journal of Affective Disorders, 151(1), 136-142. doi.org/10.1016/j.jad.2013.05.063

Öner, N. ve Le Compte, A. (1983). Durumluk Sürekli Kaygl Envanteri el kitabı. İstanbul: Boğaziçi Üniversitesi.

Raghunathan, R., \& Pham, M. T. (1999). All negative moods are not equal: Motivational influences of anxiety and sadness on decision making. Organizational Behavior and Human Decision Processes, 79(1), 56-77. doi:10.1006/0bhd.1999.2838 
Robichaud, M., \& Dugas, M. J. (2015). The generalized anxiety disorder workbook. Oakland: New Harbinger.

Sarı, S. (2007). Sürekli kaygının yordayıcıları olarak belirsizliğe tahammülsüzlük, endişe ile ilgili inançlar ve kontrol odă̆ının incelenmesi. (Yayımlanmamış yüksek lisans tezi). Hacettepe Üniversitesi, Ankara.

Sarı, S. ve Dağ, İ. (2009). Belirsizliğe tahammülsüzlük ölçeği, endişe ile ilgili olumlu inançlar ölçeği ve endişenin sonuçları ölçeğinin Türkçeye uyarlanması, geçerliliği ve güvenilirliği. Anadolu Psikiyatri Dergisi, 10, 261-270.

Seligman, L., \& Reichenberg, L. W. (2010). Theories of counseling and psychotherapy systems, strategies and skills (3rd ed.). Upper Saddle River, NJ: Pearson.

Shihata, S., Mc Evoy, P. M., \& Mullan, B. A. (2017). Pathways from uncertainty to anxiety: An evaluation of a hierarchical model of trait and disorder-specific intolerance of uncertainty on anxiety disorder symptoms. Journal of Anxiety Disorders, 45, 72-79. doi:10.1016/j.janxdis.2016.12.001

Spielberger, C. D. (1972). Anxiety as an emotional state. In C. D. Spielberger (Ed.). Anxiety: Current trends in theory and research, 1, (pp. 23-50). New York: Academic.

Sungur M. Z. (1997). Bilişsel-davranışçı terapilerin gelişim öyküsü. A. Tangör (Ed.), Psikoterapiler el kitabı içinde (ss. 50-66) İzmir: Ege Üniversitesi Psikiyatri.

Türkçapar, H. (2006). Bilişsel terapi (6. baskı). Ankara: HYB.

Werner, N. S., Duschek, S., \& Schandry, R. (2009). Relationships between affective states and decisionmaking. International Journal of Psychophysiology, 74(3), 259-265. doi:10.1016/j.ipsycho.2009.09.010

Yates, J. F., \& Estin, P. A. (1998). Decision making. In W. Bechtel \& G. Graham (Eds.), A companion to cognitive science (pp. 186-196). Malden, MA: Blackwell.

Yook, K., Kim, K. H., Suh, S. Y., \& Lee, K. S. (2010). Intolerance of uncertainty, worry, and rumination in major depressive disorder and generalized anxiety disorder. Journal of Anxiety Disorders, 24(6), 623628. doi:10.1016/j.janxdis.2010.04.00 